\title{
On the Suboptimality of Full Turnover-Based Storage
}

\author{
Yugang Yu and René B.M. de Koster
}

\begin{tabular}{|l|l|}
\hline \multicolumn{2}{|l|}{ ERIM REPORT SERIES RESEARCH IN MANAGEMENT } \\
\hline ERIM Report Series reference number & ERS-2009-051-LIS \\
\hline Publication & September 2009 \\
\hline Number of pages & 14 \\
\hline Persistent paper URL & http://hdl.handle.net/1765/16898 \\
\hline Email address corresponding author & yyugang@rsm.nl \\
\hline Address & Erasmus Research Institute of Management (ERIM) \\
& RSM Erasmus University / Erasmus School of Economics \\
& Erasmus Universiteit Rotterdam \\
& P.O.Box 1738 \\
& 3000 DR Rotterdam, The Netherlands \\
& Phone: + 31 10 408 1182 \\
& Fax: + 31 10 408 9640 \\
& Email: info@erim.eur.nl \\
& Internet: $\quad$ www.erim.eur.nl \\
\hline
\end{tabular}

Bibliographic data and classifications of all the ERIM reports are also available on the ERIM website: www.erim.eur.nl 


\section{ERASMUS RESEARCH INSTITUTE OF MANAGEMENT}

\section{REPORT SERIES}

\section{RESEARCH IN MANAGEMENT}

\begin{tabular}{|l|l|}
\hline ABSTRACT AND KEYWORDS \\
\hline Abstract & $\begin{array}{l}\text { In the past thirty years the full turnover-based storage policy as described by Hausman et al. } \\
(1976, \text { Management Science 22(6)) has been widely claimed to outperform the commonly used } \\
\text { ABC class-based storage policy, in terms of the resulting average storage and retrieval machine } \\
\text { travel time. In practice however, ABC storage is the dominant policy. Hausman et al. (1976) } \\
\text { model the turnover-based policy under the unrealistic assumption of shared storage, i.e. the } \\
\text { storage space allocated to one product can only accommodate its average inventory level; no } \\
\text { specific space is reserved to store the maximum inventory of a product. It appears that many } \\
\text { authors citing Hausman et al.'s results overlook this assumption and use the resulting storage } \\
\text { and retrieval machine travel times as if it were valid for full turnover-based storage. Full turnover- } \\
\text { based storage is a dedicated storage policy where the storage space allocated to one product } \\
\text { must accommodate its maximum inventory level. This paper adapts the travel time model of } \\
\text { Hausman et al. to accommodate full turnover-based dedicated storage. Surprisingly, the result of } \\
\text { the adapted travel time model is opposite to that of Hausman et al. (1976) but, in line with } \\
\text { practice, it supports that ABC (2- or 3-) class-based storage normally outperforms full turnover- } \\
\text { based storage. }\end{array}$ \\
\hline Distribution science, warehousing, storage policy, AS/RS \\
\hline Free Keywords & $\begin{array}{l}\text { The ERIM Report Series is distributed through the following platforms: } \\
\text { Academic Repository at Erasmus University (DEAR), DEAR ERIM Series Portal } \\
\text { Social Science Research Network (SSRN), SSRN ERIM Series Webpage } \\
\text { Research Papers in Economics (REPEC), REPEC ERIM Series Webpage }\end{array}$ \\
\hline $\begin{array}{l}\text { The electronic versions of the papers in the ERIM report Series contain bibliographic metadata } \\
\text { by the following classification systems: } \\
\text { Library of Congress Classification, (LCC) } \underline{\text { LCC Webpage }} \\
\text { Journal of Economic Literature, (JEL), JEL Webpage } \\
\text { ACM Computing Classification System CCS Webpage } \\
\text { Inspec Classification scheme (ICS), ICS Webpage }\end{array}$ \\
\hline
\end{tabular}




\title{
On the Suboptimality of Full Turnover-Based Storage
}

\author{
Yugang YU \\ Rotterdam School of Management, Erasmus University, the Netherlands, yyugang@ @rsm.nl \\ René B.M. de Koster \\ Rotterdam School of Management, Erasmus University, the Netherlands, rkoster@rsm.nl
}

In the past thirty years the full turnover-based storage policy as described by Hausman et al. (1976, Management Science 22(6)) has been widely claimed to outperform the commonly used ABC class-based storage policy, in terms of the resulting average storage and retrieval machine travel time. In practice however, ABC storage is the dominant policy. Hausman et al. (1976) model the turnover-based policy under the unrealistic assumption of shared storage, i.e. the storage space allocated to one product can only accommodate its average inventory level; no specific space is reserved to store the maximum inventory of a product. It appears that many authors citing Hausman et al.'s results overlook this assumption and use the resulting storage and retrieval machine travel times as if it were valid for full turnover-based storage. Full turnover-based storage is a dedicated storage policy where the storage space allocated to one product must accommodate its maximum inventory level. This paper adapts the travel time model of Hausman et al. to accommodate full turnover-based dedicated storage. Surprisingly, the result of the adapted travel time model is opposite to that of Hausman et al. (1976) but, in line with practice, it supports that ABC (2or 3-) class-based storage normally outperforms full turnover-based storage.

Keywords: Distribution science, warehousing; storage policy, AS/RS

\section{Introduction}

A storage assignment policy determines where in a warehouse a unit load of a certain product must be stored. The choice of a proper policy is important, as it impacts the amount of space needed to store all loads and the time needed to store and retrieve a load of a certain product. Two main classes of storage policies can be distinguished. In a dedicated (or fixed-location) storage policy each product is assigned to 
a number of storage locations that must accommodate its maximum inventory level (Tompkins et al., 2003, p 433). In a shared (or random-location) policy multiple products share some common storage locations (but not at the same time) that can accommodate about the average inventory level of these products (Tompkins et al., 2003, p 433). Hausman et al. (1976) were the first to systematically investigate the impact of different storage policies (random, full-turnover, two-class based and three-class based) on the expected unit load retrieval time (assuming a single-cycle retrieval policy), for a rack of a given size. Since then hundreds of papers have appeared on this subject dealing with various storage policies, retrieval policies, rack shapes, and retrieval equipment.

The full turnover-based storage policy stores products in warehouses according to the turnovers of individual products. A product with a higher turnover is stored in a storage location closer to the input/output (I/O) point (i.e., depot) of the warehouse. Hausman et al. (1976) calculate the retrieval travel time of this policy as a function of the ABC-demand curve. Using this travel-time model, it has been shown full turnover-based storage is "better" than the widely used two- or three-class-based storage policies. The full turnover-based storage policy has generally been accepted as the policy leading to the shortest retrieval time and has been discussed as such in many articles (e.g., Graves et al., 1977; Linn and Wysk, 1990, page 41; Eynan and Rosenblatt, 1994; Lee and Schaefer, 1997, page 16; Wen et al., 2001; Lee and Elsayed, 2005, page 1786; De Koster et al., 2007; Gu et al., 2007).

The full turnover based storage policy described by Hausman et al. (1976) essentially is a shared storage policy according to their two main assumptions: a) they use full-turnover based storage policy ("the highest-turnover pallet is assigned to the closest location" (p.631), i.e. pallet $i$ should be located exactly between pallets $i-1$ and $i+1$, if its turnover speed is between the ones of these pallets; b) The storage space available for storing all products equals the sum of their average inventory levels, $\int_{i=0}^{1} Q(i) / 2 d i$ (Eq. (9) in Hausman et al. (1976)), where $Q(i)$ is the economic order quantity. This implies on average the storage space of item $i$ equals $Q(i) / 2$. When the lot of size $Q(i)$ arrives, it must be located exactly between 
products $i-1$ and $i+1$ (products are indexed in decreasing order of turnover). However, this is not possible due to lack of space.

Next to this inconsistency, Hausman et al.'s paper has led to other problems:

- Their result do not help to explain why class-based storage is preferred in practice over full turnover based storage. This has led to several explanations in literature as why the policy is hardly applied in practice (summarized in Appendix A). These explanations, although valid, overlook a main reason: its poor performance.

- Many authors build on Hausman et al.'s results and indicate their full turnover-based storage policy is a special case of the class-based storage policy with one product per class (Rosenblatt and Eynan, 1989; Eynan and Rosenblatt, 1994; Van den Berg and Zijm, 1999). However, in class-based storage the storage space for one class is not shared with that of other classes. One product per class requires a storage space of $Q(i)$ units for product $i$,

To our knowledge, these problems have not been addressed in literature in the past thirty years. The assumptions, including their inconsistency have been taken for granted by other authors. Moreover, the travel time model and its results have had significant impact on research in warehousing. Many authors build on results of Hausmann et al., without questioning the underlying assumptions. We give some examples:

- The travel time model of Hausman et al. (1976) is used or extended by many other papers (e.g., Thonemann and Brandeau, 1998; Van den Berg and Gademann, 2000; Park et al., 2003; Yu and De Koster, 2009) for different systems. However, these authors explicitly or implicitly interpret the full turnover based storage policy of Hausman et al. (1976) is dedicated storage.

- The results of Hausman et al. (1976) are cited to show full turnover based storage is better than class based storage. But simultaneously, those citing papers or books directly indicate that the full turnover-based storage policy of Hausman et al. (1976) is dedicated storage (Linn and Wysk, 1990, page 40; Park, 1999, page 1011; Van den Berg and Zijm, 1999, page 526; Malmborg, 2000, page 
4601; Van den Berg and Gademann, 2000, page 1340; Koh et al., 2002, page 503; Park et al., 2003, pages 343 and 348; Gu et al., 2007, page 8; Roodbergen and Vis, 2009, page 349).

- The full turnover-based storage policy of Hausman et al. (1976) is claimed to be a Cube-per-Order Index (COI) policy (in such a policy products are sorted on decreasing turnover per unit load, see (Heskett, 1963) by some papers (e.g. Lee and Elsayed, 2005; Roodbergen and Vis, 2009). However the COI policy is a dedicated storage policy (Van den Berg, 1999, pages 754-755; Lee and Elsayed, 2005, page 1790).

In this paper we adapt Hausman et al.'s (1976) travel time model to include full turnover-based dedicated storage by removing assumption b) indicated in the above.. This leads to the following contributions:

- We derive a travel time model for full turnover based dedicated storage (or the COI policy) as a function of the $\mathrm{ABC}$ curve. It can be used to compare the full turnover based dedicated storage with class-based storage and random storage because the travel time models of those policies are expressed as a function of the ABC-demand curve (using the expression in Hausman et al. (1976), page 633). The current travel time models for the COI policy (Heskett, 1963) can not make this comparison because they are not a function of the same demand curve.

- With the adapted travel time model we find that our results differ from those of Hausman et al. (1976). Our adapted travel time model theoretically confirms that the full turnover-based storage (or COI) policy is normally outperformed by 2- or 3-class-based storage, and can even be worse than random storage if the $\mathrm{ABC}$-demand curve is not skewed.

In the following, we first describe the research problem. In Section 3, the travel time model developed by Hausman et al. (1976) is given. In Section 4, we adapt their travel time model. Finally, in Section 5, a numerical example is given illustrating full-turnover based dedicated storage rarely outperforms classbased storage. Section 6 concludes the paper. 


\section{Problem description}

Following Hausman et al. (1976), we consider a basic automated warehousing system: an automated storage/retrieval system (AS/RS) consisting of a storage/retrieval (S/R) machine, a storage rack, and one depot where all products enter and leave the system. The system works as follows: incoming products (finished goods, work-in-process, or raw materials) are assigned to unit loads (e.g., pallets) before arriving at the AS/RS system. When pallets arrive at the depot of the system, the machine can pick the pallets and move simultaneously in horizontal and vertical dimensions to store them at a given storage location in the storage rack. Upon request of a pallet, the machine moves to its location, retrieves it and brings it to the depot.

In accordance with Hausman et al. (1976), the studied system has the following properties:

1) All storage locations are the same size as the pallets themselves. Each pallet contains only one product.

2) The depot is at the lower-left side of the storage rack.

3) The storage rack is "square" in time; the time for the machine to move from the depot to the most distant bay equals the time from the depot to the highest tier. The rack size is normalized to be 1 and the distances of travel times are distributed between $(0,1]$ in two dimensions.

4) The capacity of the machine is one unit load and it operates in a single-command mode; the machine either stores or retrieves a pallet each time.

5) The pickup/deposit time for the machine to load/unload a pallet at the depot and storage/retrieval location is ignored.

6) The turnover frequency of each product is known and constant through time. The turnover of a product equals the number of times the product is stored or retrieved in a given time period (e.g. week, month, and year).

7) Product inventories are replenished according to the EOQ model where the demands (in pallets) of products are deterministic and determined by the ABC curve given in Eq. (1). 
8) The products are ranked according to their marginal contribution to the total demand using the $\mathrm{ABC}$ curve. The product that has a smaller contribution is ranked/indexed with a larger number. The $\mathrm{ABC}$ curve is a plot of ranked cumulative percentage demand per unit time, $G(i)$, and formulated by:

$$
G(i)=i^{s}=\int_{0}^{i} D(j) d j / \int_{0}^{1} D(j) d j, \quad \text { for } 0<s \leq 1,
$$

where $i$ is the product at the $i^{\text {th }}$ percentile in the ranked sequence of all product types, and $D(i)$ is the demand of product $i$ per unit time. The smaller $s$ is, the skewer the ABC curve is.

Without loss of generality, assuming that the total demand $\int_{0}^{1} D(j) d j=1$ (Hausman et al., 1976), we have:

$$
D(i)=d G(i) / d i=s i^{s-1}, \quad 1<i \leq 1 .
$$

The research question is: given the above system properties and the product demands determined by Eq. (2), what is the expected one-way travel time for the machine to store and retrieve a random pallet by using full turnover-based storage?

\section{Models for full turnover-based storage from Hausman et al (1976)}

The expected one-way travel time for a random pallet is determined by the turnover of each pallet and the one-way travel time between every pallet location and the depot.

\section{Turnover of each pallet:}

With the classic EOQ model, the economic order quantity (in pallets) of product $i$ is $Q(i)=(2 K D(i))^{1 / 2}$ where $K$ is the ratio of order cost to holding cost and assumed the same for all products. The average inventory (in pallets) of product $i$ is $Q(i) / 2$. The average inventory level of all products, $L$, therefore is

$$
\left.L=\int_{i=0}^{1} Q(i) / 2 d i=\int_{i=0}^{1}(2 K D(i))^{1 / 2} / 2\right) d i=(2 K s)^{1 / 2} /(s+1)
$$

Hausman et al. (1976, pp. 634) assume the total storage area ( measured in number of pallet locations) required for storing all products, $A$, equals $L$, which yields:

$$
A=L=(2 K s)^{1 / 2} /(s+1) .
$$

Therefore, the relationship between pallet $j, j \in(0, A]$ and product $i$ can be determined by: 


$$
\left.j=\int_{k=0}^{i(j)}(2 K D(k))^{1 / 2} / 2\right) d k
$$$$
\text { that is, } \quad i(j)=\left[(s+1)^{2} j^{2} /(2 K s)\right]^{1 /(s+1)} \text {. }
$$

Without loss of generality, $j$ is rescaled from $(0, L]$ to $(0,1]$ by replacing $j$ with $j^{*} L$ in Eq. (6), and we have

$$
i(j)=\left[\frac{(s+1)^{2}\left[(2 K s)^{1 / 2} /(s+1) j\right]^{2}}{2 K s}\right]^{1 /(s+1)}=j^{2 /(s+1)}
$$

Substituting Eq. (7) into Eq. (2), the demand rate for the product on pallet $j$, denoted by $D_{j}^{\prime}$ is:

$$
D_{j}^{\prime}=\left.D_{i}\right|_{i=i(j)}=s j^{2(s-1) /(s+1)}, j \in(0,1] .
$$

Product $i$ occupies a storage space of $Q(i) / 2$ pallets on average. Therefore, given $Q(i)=(2 K D(i))^{1 / 2}$ and Eq. (8), the turnover rate of pallet $j$ as a function of $j, \lambda(j)$, is determined by:

$$
\lambda(j)=D(i) /(Q(i) / 2)=(2 D(i) / K)^{1 / 2}=(2 s / K)^{1 / 2} j^{(s-1) /(s+1)} .
$$

\section{One-way travel time of pallet $j$ :}

As the system is square in time and the machine can simultaneously move in horizontal and vertical dimensions, the travel time of moving the $j$ th pallet to the depot, denoted by $y(j)$, is:

$$
y(j)=\sqrt{j} .
$$

\section{Expected one-way travel time of pallets:}

Because $j$ is scaled in $(0,1]$, the expected one-way travel time for storing/retrieving a pallet by Hausman, et al. (1976), denoted by $T_{H S G}$, is

$$
T_{H S G}=\frac{\int_{0}^{1} \lambda(j) y(j) d j}{\int_{0}^{1} \lambda(j) d j}=\frac{4 s}{5 s+1} .
$$

If $s=1, T_{H S G}=2 / 3=T_{R}$ where $T_{R}$ is the expected one-way travel time for random storage. 


\section{Adapted model for full turnover-based storage}

Different from the travel time model in Hausman et al. (1976), we adapt their travel time model of full turnover-based storage by coupling it with dedicated storage. Each product $i$ is dedicated to a predetermined storage area. The total storage area (measured in number of pallet locations) in the system required for storing all products therefore is not $A$ in Eq. (4), but $\bar{A}$ :

$$
\bar{A}=\int_{i=0}^{1} Q(i) d i=2 L=(8 K s)^{1 / 2} /(s+1)
$$

Therefore, the relationship between pallet $j, j \in(0, \bar{A}]$, and product type $i$ changes in:

$$
\begin{gathered}
j=\int_{k=0}^{i(j)}(2 K D(k))^{1 / 2} d k, \\
\text { that is, } \quad i(j)=\left[\frac{(s+1)^{2} j^{2}}{8 K s}\right]^{1 /(s+1)} .
\end{gathered}
$$

In order to compare our results with those of Hausman et al (1976), we also rescale $j$ by replacing $j$ with $j^{*} L$ in Eq. (14):

$$
i(j)=(j / 2)^{2 /(s+1)}
$$

where $j$ is correspondingly rescaled to $(0,2 L / L]=(0,2]$. Note this differs from $j \in(0,1]$ in Eq. (7).

Substituting Eq. (15) into Eq. (2), the demand rate for the product on pallet $j, D_{j}^{\prime}$ becomes

$$
D_{j}^{\prime}=D_{i} \mathrm{I}_{i=i(j)}=s(j / 2)^{2(s-1) /(s+1)}, j \in(0,2]
$$

For each product type $i$, as the storage space (in number of pallets) is $Q(i)$ instead of $Q(i) / 2$ in Hausman et al (1976), the turnover rate of the $j$ th pallet, $\bar{\lambda}(j)$, therefore becomes:

$$
\bar{\lambda}(j)=D(i) / Q(i)=(D(i) /(2 K))^{1 / 2}=2^{-(s-1) /(s+1)-1 / 2} \sqrt{s / K} j^{(s-1) /(s+1)} .
$$

Because $j \in(0,2]$, using Eqs. (17) and (10), the expected one-way travel time for full turnover-based storage, denoted by $T_{\text {adapt }}$, becomes:

$$
T_{\text {adapt }}=\frac{\int_{0}^{2} \bar{\lambda}(j) y(j) d j}{\int_{0}^{2} \bar{\lambda}(j) d j}=\frac{4 \sqrt{2} s}{5 s+1},
$$

Comparing Eq. (18) and Eq. (11), we have $T_{\text {adapt }}=\sqrt{2} T_{H S G}$, and $T_{\text {adapt }}=0.9428$ at $s=1$. 


\section{Experiments}

This section evaluates the performance of the adapted model for full turnover-based storage, and compares it with some popular storage policies: random storage, two-class based storage, three-class based storage, and Eq. (11) for full turnover-based storage given by Hausman et al (1976). The formulae for class-based and random storage here are from Hausman et al (1976), and the optimal solutions for class-based storage are determined by the algorithms in Rosenblatt \& Eynan (1989).

The corresponding results are shown in Figure 1 for all storage policies, with different types of ABC curves.

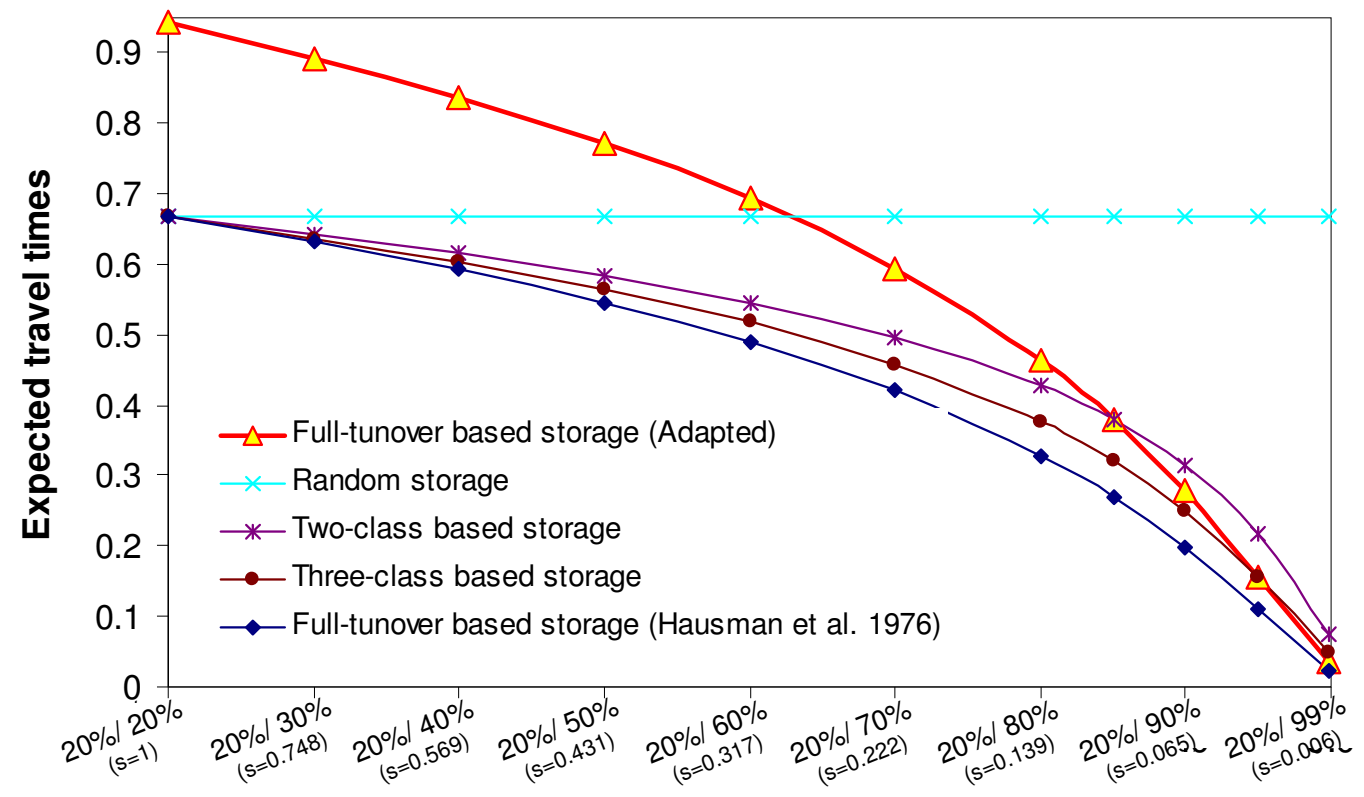

\section{Types of the ABC curve}

Note. (i) $x \% / y \%$ implies that $\mathrm{x} \%$ of the products in inventory represent $y \%$ of the total demand; (ii) the corresponding values of " $s$ " is determined by Equation (1) (i.e., $(x \%)^{s}=y \%$ ).

\section{Figure 1. Expected Travel Times of different storage policies}

From Figure 1, we make the following observations:

- Two-class based storage outperforms full turnover-based storage (adapted) if the ABC curve is not skewer than 20\%/85\%. Three-class based storage outperforms full-turnover based storage (adapted) if the $\mathrm{ABC}$ curve is not skewer than $20 \% / 95 \%$. Even random storage can outperform full-turnover based storage (adapted) if the ABC curve is not skewer than about $20 \% / 63 \%$. In fact, full turnover- 
based storage is only interesting to apply when a very small part of all products dominates all storage and retrieval requests.

- Hausman et al. (1976)'s expression for the travel time of full turnover-based storage provides a lower bound of the expected travel times for random storage, class-based storage and our adapted travel time formula in Eq. (18) for full turnover based dedicated storage.

\section{Conclusion}

In this paper we adapt the travel time model of Hausman et al (1976) for full turnover-based storage in order to reflect the practice that full turnover-based storage is coupled with dedicated storage. Using the adapted travel time model, our results confirm that full turnover-based storage is normally worse than the widely used two- or three-class based storage policies in terms of the expected travel times. Our result explains the mismatch between theory and practice; in theory the full-turnover based storage "outperforms" class-based storage, but in practice it is much less popular.

The travel time model of Hausman et al.(1976) for full turnover-based storage provides a lower bound of the expected travel times for all turnover-based storage policies. It is very useful to assess the performance of other storage policies.

More research like this is called for. We here give some examples:

- In our experiments, the travel time models for the two- and three-class based storage polices are also taken from Hausman et al. (1976). The shared storage space for products in each class is then given based on the average inventory level of each product: $Q(i) / 2$. This is a reasonable approximation if the number of classes is few and the number of products is large. However, if the number of classes is large and the number of products per class is rather small, the real average storage space consumption for each product may be significantly larger than its average inventory level: $Q(i) / 2$. In this case, a modification of the travel time model of Hausman et al.(1976) for class based storage is needed, which may lead to results quite different from those in literature. For example, a larger number of classes may give a longer expected travel time of a load. However, such a study would be very 
complex as the gross space consumption of all products depends not only on the number of products and of classes in a given system, but also on replenishment cycles and order quantities of individual products.

- For different types of distribution and warehousing systems, the research about storage policies has been extensively investigated in hundreds of papers (see Gu et al., 2007), but, to our knowledge, space consumption combined with storage policies has been almost overlooked.

- A larger uncertainty in product demand normally leads to more space consumption of the product in a warehouse. Further research combining service levels of products with uncertain demand with storage policies and storage space consumption would therefore be very valuable.

\section{Appendix A. Other explanations why full turnover-based storage is not popular in practice:}

In the literature the following arguments are used to explain why the full turnover-based storage is little applied in the real life world, although it should theoretically be better

- In practice the turnover of every pallet to be stored in the system is not known (Hausman et al., 1976, page 635). This argument is less convincing nowadays as warehouse management systems (WMS) have been widely used to track the information of every product.

- In practice the turnover of every pallet to be stored in the system is not constant over time. The demand frequencies changes constantly. A change in frequency and any addition of a new product to the system may require a large number of load reshuffles to bring them back in line with the full turnover-based rule. To prevent excessive repositioning, class-based storage is preferred in practice. (Hausman et al., 1976, page 635; Tompkins et al., 2003, page 435; De Koster et al., 2007, page 9; Roodbergen and Vis, 2009, page 349).

- In practice there is a tradeoff between travel time and cost of space. Due to the relatively high space consumption of full turnover-based dedicated storage, class-based storage is more popular as it can yield the short travel time benefit of dedicated storage and the space benefits of random storage (Malmborg, 2000, page 4601; Tompkins et al., 2003, page 435; Gu et al., 2007, page 9). However, 
with our results, this argument is incorrect as full turnover-based dedicated storage normally has a longer travel time than class based storage since it needs more storage space.

\section{References}

De Koster, R., Le-Duc, T., Roodbergen, K. J. (2007). Design and control of warehouse order picking: A literature review. European Journal of Operational Research, 182(2), 481-501. Eynan, A., Rosenblatt, M. J. (1994). Establishing Zones in Single-Command Class-Based Rectangular AS/RS. IIE Transactions, 26(1), 38-46.

Graves, S. C., Hausman, W. H., Schwarz, L. B. (1977). Storage-retrieval interleaving in automatic warehousing systems. Management Science, 23, 935-945.

Gu, J. X., Goetschalckx, M., McGinnis, L. F. (2007). Research on warehouse operation: A comprehensive review. European Journal of Operational Research, 177(1), 1-21.

Hausman, W. H., Schwarz, L. B., Graves, S. C. (1976). Optimal storage assignment in automatic warehousing systems. Management Science, 22(6), 629-638.

Heskett, J. L. (1963). Cube-per-order index - a key to warehouse stock location. Transportation and Distribution Management, 3, 27-31.

Koh, S. G., Kim, B. S., Kim, B. N. (2002). Travel time model for the warehousing system with a tower crane S/R machine. Computers \& Industrial Engineering, 43, 495-507.

Lee, H. F., Schaefer, S. K. (1997). Sequencing methods for automated storage and retrieval systems with dedicated storage. Computers \& Industrial Engineering, 32(2), 351-362.

Lee, M. K., Elsayed, E. A. (2005). Optimization of warehouse storage capacity under a dedicated storage policy. International Journal of Production Research, 43(9), 1785-1805.

Linn, R. J., Wysk, R. A. (1990). An Expert System Based Controller for an Automated StorageRetrieval System. International Journal of Production Research, 28(4), 735-756. 
Malmborg, C. J. (2000). Interleaving models for the analysis of twin shuttle automated storage and retrieval systems. International Journal of Production Research, 38(18), 4599-4610.

Park, B. C. (1999). Optimal dwell point policies for automated storage/retrieval systems with dedicated storage. IIE Transactions, 31(10), 1011-1013.

Park, B. C., Foley, R. D., White, J. A., Frazelle, E. H. (2003). Dual command travel times and miniload system throughput with turnover-based storage. IIE Transactions, 35(4), 343-355.

Roodbergen, K. J., Vis, I. F. A. (2009). A survey of literature on automated storage and retrieval systems. European Journal of Operational Research, 194(2), 343-362.

Rosenblatt, M. J., Eynan, A. (1989). Deriving the optimal boundaries for class-based automatic storage/retrieval systems. Management Science, 35(12), 1519-1524.

Thonemann, U. W., Brandeau, M. L. (1998). Optimal storage assignment policies for automated storage and retrieval systems with stochastic demands. Management Science, 44(1), 142-148.

Tompkins, J. A., White, J. A., Bozer, Y. A., Tanchoco, J. M. A. (2003). Facilities Planning. New York: John Wiley and Sons.

Van den Berg, J. P. (1999). A literature survey on planning and control of warehousing systems. IIE Transactions, 31(8), 751-762.

Van den Berg, J. P., Gademann, A. J. R. M. (2000). Simulation study of an automated storage/retrieval system. International Journal of Production Research, 38(6), 1339-1356.

Van den Berg, J. P., Zijm, W. H. M. (1999). Models for warehouse management: Classification and examples. International Journal of Production Economics, 59(1-3), 519-528.

Wen, U. P., Chang, D. T., Chen, S. P. (2001). The impact of acceleration/deceleration on traveltime models in class-based automated S/R systems. IIE Transactions, 33(7), 599-608. 
Yu, Y., De Koster, R. B. M. (2009). Designing an optimal turnover-based storage rack for a 3D compact automated storage and retrieval system. International Journal of Production Research, 47(6), 1551-1571. 


\section{Publications in the Report Series Research* in Management}

\section{ERIM Research Program: "Business Processes, Logistics and Information Systems"}

\section{9}

How to Normalize Co-Occurrence Data? An Analysis of Some Well-Known Similarity Measures

Nees Jan van Eck and Ludo Waltman

ERS-2009-001-LIS

http://hdl.handle.net/1765/14528

Spare Parts Logistics and Installed Base Information

Muhammad N. Jalil, Rob A. Zuidwijk, Moritz Fleischmann, and Jo A.E.E. van Nunen

ERS-2009-002-LIS

http://hdl.handle.net/1765/14529

Open Location Management in Automated Warehousing Systems

Yugang YU and René B.M. de Koster

ERS-2009-004-LIS

http://hdl.handle.net/1765/14615

VOSviewer: A Computer Program for Bibliometric Mapping

Nees Jan van Eck and Ludo Waltman

ERS-2009-005-LIS

http://hdl.handle.net/1765/14841

Nash Game Model for Optimizing Market Strategies, Configuration of Platform Products in a Vendor Managed Inventory (VMI) Supply Chain for a Product Family

Yugang Yu and George Q. Huang

ERS-2009-009-LIS

http://hdl.handle.net/1765/15029

A Mathematical Analysis of the Long-run Behavior of Genetic Algorithms for Social Modeling Ludo Waltman and Nees Jan van Eck

ERS-2009-011-LIS

http://hdl.handle.net/1765/15181

A Taxonomy of Bibliometric Performance Indicators Based on the Property of Consistency

Ludo Waltman and Nees Jan van Eck

ERS-2009-014-LIS

http://hdl.handle.net/1765/15182

A Stochastic Dynamic Programming Approach to Revenue Management in a Make-to-Stock Production System Rainer Quante, Moritz Fleischmann, and Herbert Meyr

ERS-2009-015-LIS

http://hdl.handle.net/1765/15183

Some Comments on Egghe's Derivation of the Impact Factor Distribution

Ludo Waltman and Nees Jan van Eck

ERS-2009-016-LIS

http://hdl.handle.net/1765/15184

The Value of RFID Technology Enabled Information to Manage Perishables

Michael Ketzenberg, and Jacqueline Bloemhof

ERS-2009-020-LIS

http://hdl.handle.net/1765/15412 
The Environmental Gains of Remanufacturing: Evidence from the Computer and Mobile Industry J. Quariguasi Frota Neto, and J.M. Bloemhof

ERS-2009-024-LIS

http://hdl.handle.net/1765/15912

Economic Modeling Using Evolutionary Algorithms: The Effect of a Binary Encoding of Strategies Ludo Waltman, Nees Jan van Eck, Rommert Dekker, and Uzay Kaymak

ERS-2009-028-LIS

http://hdl.handle.net/1765/16014

Language Selection Policies in International Standardization - Perception of the IEC Member Countries

Hans Teichmann and Henk J. de Vries

ERS-2009-031-LIS

http://hdl.handle.net/1765/16038

Dominant Design or Multiple Designs: The Flash Memory Card Case

Henk J. de Vries, Joost P.M. de Ruijter and Najim Argam

ERS-2009-032-LIS

http://hdl.handle.net/1765/16039

Standards Education Policy Development: Observations based on APEC Research

Donggeun Choi, Henk J. de Vries and Danbee Kim

ERS-2009-033-LIS

http://hdl.handle.net/1765/16040

Scheduling deliveries under uncertainty

Adriana F. Gabor, Rommert Dekker, Timon van Dijk, and Peter van Scheepstal

ERS-2009-040-LIS

http://hdl.handle.net/1765/16236

A simple alternative to the $h$-index

Ludo Waltman and Nees Jan van Eck

ERS-2009-043-LIS

http://hdl.handle.net/1765/16556

Disruption Management of Rolling Stock in Passenger Railway Transportation

Lars Kjaer Nielsen and Gabor Maroti

ERS-2009-046-LIS

http://hdl.handle.net/1765/16557

A Temporal Web Ontology Language

Viorel Milea, Flavius Frasincar, and Uzay Kaymak

ERS-2009-050-LIS

http://hdl.handle.net/1765/16794

On the Suboptimality of Full Turnover-Based Storage

Yugang Yu and René B.M. de Koster

ERS-2009-051-LIS

http://hdl.handle.net/1765/16898

* A complete overview of the ERIM Report Series Research in Management: https://ep.eur.nl/handle/1765/1

ERIM Research Programs:

LIS Business Processes, Logistics and Information Systems

ORG Organizing for Performance

MKT Marketing

F\&A Finance and Accounting

STR Strategy and Entrepreneurship 